\title{
IMPROVEMENT OF THE TECHNIQUE FOR PREDICTING THE TEMPERATURE MODES OF LOW-POTENTIAL GEOTHERMAL WELLS
}

\author{
P.V. Iakovlev ${ }^{1, *}$, I.S .Churkin ${ }^{1}$, and V.V. Andreev ${ }^{1}$ \\ ${ }^{1}$ Saint Petersburg Mining University, Saint Petersburg, Russia
}

\begin{abstract}
The experience of operating geothermal thermal power plants shows that during the first 5 years, their economic performance deteriorates, because there is a change in the temperature field of the soil. It is also important to consider: seasonal cyclical changes in the heat load and possible reversal of the heat flow when switching from heating to air conditioning and vice versa. An option is considered, which, when the coolant fills the well, directly contacting the surface of the casing. During well operation, seasonal or technological changes in well load are taken into account. The well is operating in reverse mode. The conditions for calculation are determined by the alternation of the periods of turning on the heat pump with the cyclical periods of stopping, determined by the season. Research have shown that as a result of longterm operation of a geothermal well in a cyclic mode of thermal loading, there are changes of a temperature field of the rock surrounding a well, with effect of interference of thermal waves, leading to accumulation of heat. Based on the processing of the results obtained criterion equations for calculating the dimensionless temperature of the well at the time of completion of the cycle of heat supply or removal, as the corresponding largest temperature difference heat pump. The received equations allow to specify calculation of technical and economic indicators taking into account duration of geothermal well operation and its mode.
\end{abstract}

\section{Introduction}

Geothermal heat of the earth is one of the choices of the renewable energy sources. The relevance of the topic is confirmed by many studies [1-19]. However, high potential geothermal sources with temperatures of $300^{\circ} \mathrm{C}$ and more occupy only $10 \%$ of the land and are often located in the low population territories with highvolcanic and seismic activities. The rest of territories has only low potential sources of geothermal energy with temperatures $15 \div 20^{\circ} \mathrm{C}$ at depth of $50 \div 100$ and average density of heat flow $50 \mathrm{~mW} / \mathrm{m}^{2}$ [1].

The use of low potential heat for heating or airconditioning is possible only when using heat pumps that require additional energy costs.

Designing geothermal holes in most cases downgrade to solve the issue of non-permanent thermal conductivity [2]. Experience in operating geothermal thermal power plants shows that during the first 5 years, their economic performance is deteriorating, because there is a change in the soil temperature field [2]. Analysis of the processes of heat exchange of the geothermal well and the rock surrounding it allows to identify the following reasons for inconsistencies between the results of calculations and operating modes of real geothermal wells:
1. High thermal resistance of the soil during continuous operation of the well leads to the accumulation of heat;

2. Seasonal cyclic changes in heat load;

3. Formation of heat waves in the rock surrounding the well, the interference of which affects the temperature regime of the well;

4. In some units, the heat flow is reversed when switching from heating to air conditioning and vice versa.

Taking into account these conditions, geothermal well is considered an accumulator of heat energy more than a means of obtaining heat energy of the earth, and the system design methodology should take into account the heat capacity of the ground and the heat flow of the earth.

\section{Methods}

The well model in the rock surrounding the well is taken as a cylindrical body consisting of several contours [3]. Figures $1 \mathrm{a}$ and $1 \mathrm{~b}$ show the model of the operating soil and the boundaries of the casing string, which represents the boundaries of the operating well. The outer boundary of the contour (the contour of the influence of the well) $q$ $=\mathrm{r}$ is determined by the results of the studies at the distance where the influence of the well on the

Corresponding author: yakovlev pv@pers.spmi.ru 
background temperature field is small. The inner boundary is the casing string of the well, through the wall of which heat exchange occurs between the circulating coolant and the ground.

Calculated model of geothermal well is shown in Fig. 1.

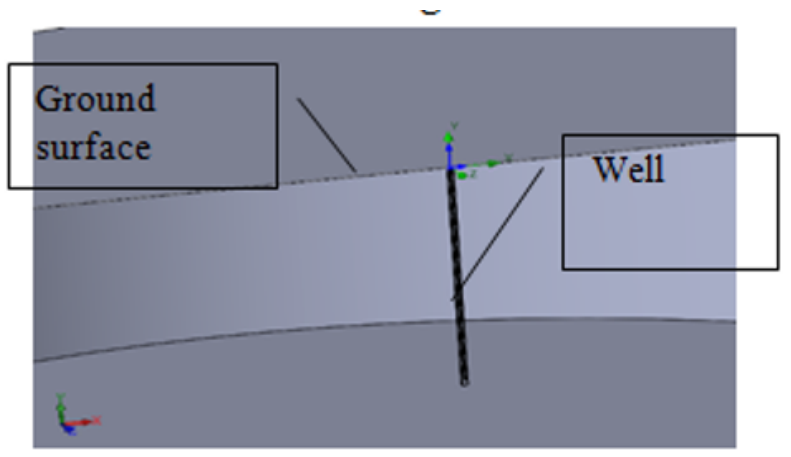

a)

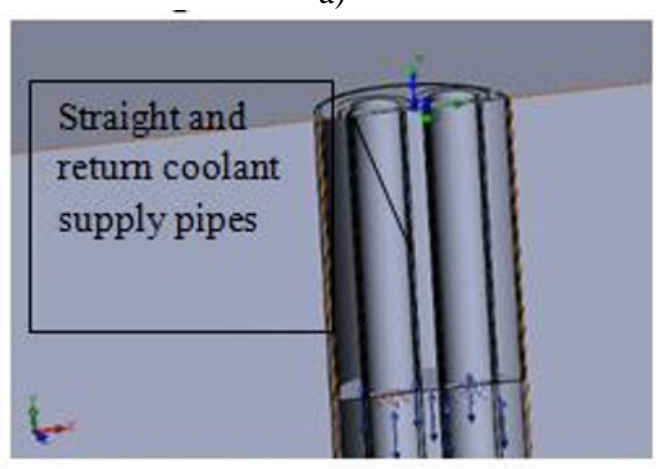

b)

Fig. 1. Calculated model of geothermal well: a - general view; $\mathrm{b}$ - straight and return coolant supply pipes.

Considering three variants of implementation of heat exchange between heat transfer medium from heat pump and the rock surrounding the well. The first variant straight and return pipes of the coolant supply are located in the casing filled with air. The second variant the well is filled with water to intensify heat exchange. In the third variant - the coolant fills the well, directly contacting with the surface of the casing.

The following temperatures of the coolant are taken into account: the temperature at the exit of the heat pump is $0^{\circ} \mathrm{C}$, the temperature of the coolant in the return pipe is $5^{\circ} \mathrm{C}$, the background temperature is $15^{\circ} \mathrm{C}$.

As a result of calculations, we get a classic temperature distribution around the well, which follow the logarithmic law. Fig. 2 shows the temperature changes for the three options.

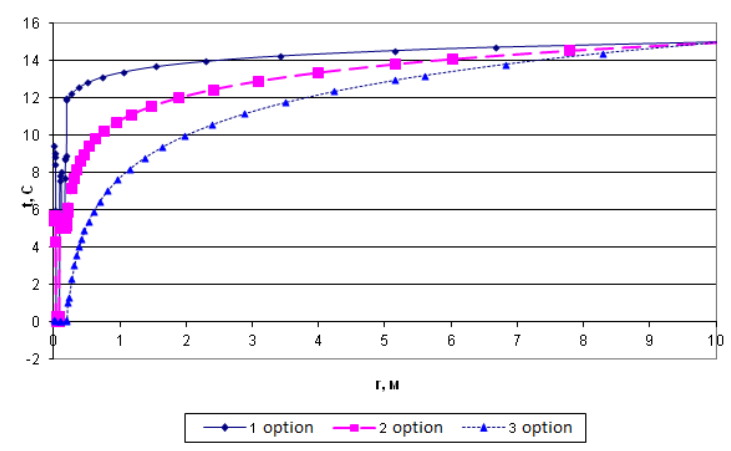

Fig. 2. the temperature changes in the rocks surrounding the well: 1 - supply of coolant by two-pipe scheme in the casing filled with air; 2 - supply of coolant by two-pipe scheme in the casing filled with water; 3 - supply of coolant in the casing.

In further calculations, only the third option is used, as an option with the most efficient heat exchange.

Fig. 3 shows the design grid of the geothermal well.

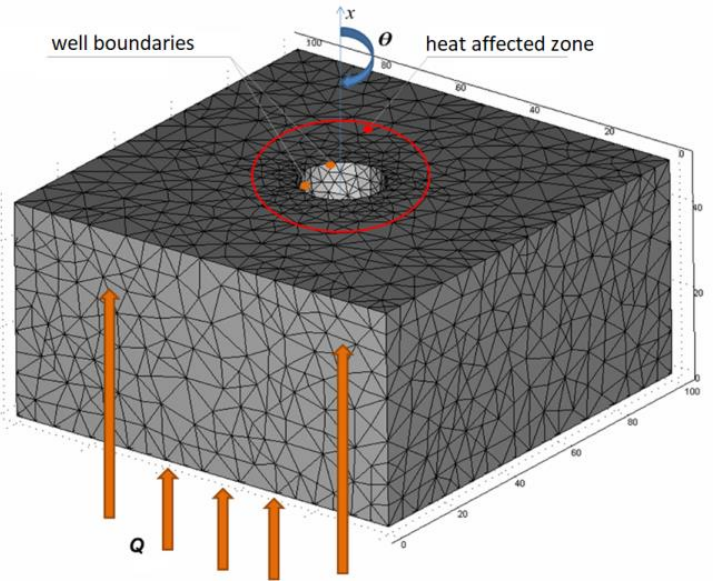

Fig. 3. Calculation grid of geothermal well: Qbackground background ground flow, $\mathrm{W} / \mathrm{m} 2 ; \mathrm{x}, \Theta, \mathrm{r}$ - cylindrical coordinate system.

Calculation of the temperature field of the rock surrounding the well is reduced to solving the equation of non-stationary heat conductivity [4]. In the cylindrical coordinate system, which is typical for vertical borehole, symmetric about the axis, the equation of unsteady heat conduction with heat sources and sinks has the form [4]:

$$
\frac{\partial t}{\partial \tau}=a\left(\frac{\partial^{2} t}{\partial x^{2}}+\frac{\partial^{2} t}{\partial r^{2}}+\frac{1}{r} \cdot \frac{\partial t}{\partial r}\right)+\frac{q_{v}}{c}
$$

$\mathrm{t}$ - ground temperature, ${ }^{\circ} \mathrm{C}$; time, $\mathrm{s}$; a - temperature diffusivity , $\mathrm{m} 2 / \mathrm{sec} ; \mathrm{r}$ - radial coordinate, $\mathrm{m} ; \mathrm{x}$ - vertical coordinate, $\mathrm{m} ; \mathrm{q}_{\mathrm{v}}$-sources and heat sinks due to heat fluxes of the earth and heat release through the surface, $\mathrm{W} / \mathrm{m} 2$.

When a well is operating with seasonal or technological changes in the load and equipment shutdowns, the initial conditions for calculating the temperature of each of the equipment operation cycles are determined by the formed temperature field after the previous cycles. 


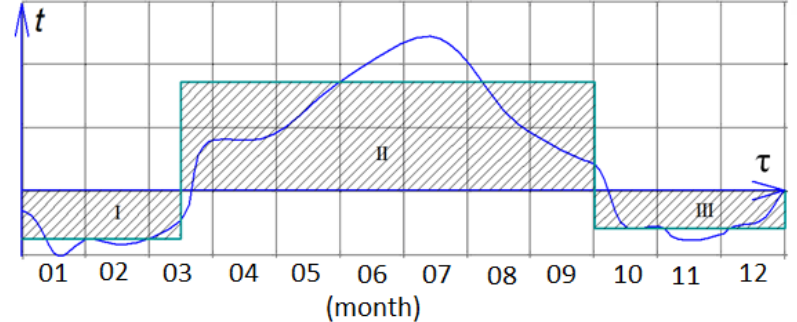

Fig. 4. Distribution of thermal loads of the well during the year.

The significant thermal inertia of the rock surrounding the well allowed to simplify the task by replacing the equipment load characteristics with discrete sections while maintaining the thermal balance. For example, shown in Fig. 4. It is suggested to replace the loading curve with equivalent discrete sections I, II, III. Calculations have shown, that the actual characteristic of equipment operation during a year can be replaced with 3-5 equivalent discrete sites with constant thermal load without significant loss of accuracy. At the initial stage of geothermal well operation the background ground temperature is the same at any distance from the well.

$$
t(r, 0)=t_{0}
$$

$t_{0}$ - Background ground temperature, ${ }^{\circ} \mathrm{C}$.

If the geothermal well is used cyclically only in the mode of heat removal or supply, when switching off, the heat pump will begin to align the temperature field, and the initial conditions for the second stage will be a complex temperature field formed by the stationary operation of the heat pump during the first calculation period $0<\tau<\tau_{1}$ :

$$
t=t_{0}\left(r, \tau_{1}\right)
$$

$\tau_{1}-$ end time of the first stage, sec.

At the moment of switching on the heat pump after a break, the initial condition for further calculation will be a complex temperature field formed after the cooling of the rock surrounding the well in the period of $\tau_{1}<\tau<\tau_{2}$ :

$$
t=t_{0}\left(r, \tau_{2}\right)
$$

$\tau 2$ - heat pump on time after break, sec;

Calculation scheme of heat pump operation with change of heat flow direction differs by appearance of stages with a changed sign of heat flow direction.

Further calculation is carried out in the same way with alternating cycles of switching on and off the heat pump. Obviously, the temperature field tends to a quasistationary state, in which the temperature changes cyclically according to the established law, which can be approximated by the function $f(r)$ and has the average temperature value calculated for the design of a geothermal system $\bar{t}(\tau)$ :

$$
t(r, \tau)=f(x)
$$

In accordance with the accepted assumptions, the following boundary conditions have been adopted:

- the first stage, on the remote contour in the area of no influence of wells and the temperature equal to its background value:

$$
\mathrm{t}(\infty, \tau)=\mathrm{t}\left(\mathrm{r}_{\mathrm{k}}, \tau\right)=\mathrm{t}_{0}=\mathrm{t}_{\mathrm{bg}},
$$

$\mathrm{t}_{\mathrm{bg}}$ - background ground temperature, ${ }^{\circ} \mathrm{C}$;

- the second stage on the lower forming calculation cylinder - the Earth's thermal flow is taken constant:

$$
-\lambda \frac{\partial t(r, \tau)}{\partial r}=q
$$

- the second stage on the surface of the well casing from the condition of primary supply of heat energy to consumers:

1. with a heat pump running:

$$
-\lambda \frac{\partial t\left(r_{c}, \tau\right)}{\partial r}=q
$$

$\lambda$ - heat transfer coefficient, $\mathrm{W} / \mathrm{m} \cdot{ }^{\circ} \mathrm{C}$

2. when a heat pump is not running:

$$
\frac{\partial t\left(r_{c}, \tau\right)}{\partial r}=0
$$

The boundary conditions of the third stage are formed on the surface of the earth, but due to the fact that the heat transfer coefficient on the surface is much higher than the heat transfer coefficient of the soil from the surface to the heat-exchange part of the well, boundary conditions of the first stage are accepted.

$$
\mathrm{t}(\mathrm{r}, \tau)=\mathrm{t}_{\text {climate }}
$$

$\mathrm{t}_{\text {climate }}$ - average annual temperature on the Earth's surface, ${ }^{\circ} \mathrm{C}$.

Calculation conditions define the alternation of the heat pump activation periods with the cyclical shutdown periods determined by the season. The time to reach quasi-stationary mode was determined by calculation and is within 5 years, which is also confirmed by operational parameters of operating systems [3]. The maximum or minimum, depending on the direction of heat flow, temperatures of well wall are reached by the end of the cycle, for example, by the end of heating season. In this regard, to determine operational characteristics, temperatures at this point of time were fixed. The range of heat flow densities is accepted by values of active wells in the range from 100 to 500 $\mathrm{W} / \mathrm{m} 2$.

The results were processed using the theory of similarity in a criterial form. In contrast to existing solutions [5], the purpose of the obtained criterion equation is to determine the temperature of the well wall after the completion of the next cycle of switching on or 
off the heat pump. The equation of calculation of dimensionless temperature in this case has the form:

$$
\Theta=\frac{t_{w e l l}-\bar{t}_{a m}}{t_{b g}-t_{a m}}
$$

$\bar{t}_{a m}$ - average annual climatic ambient temperature, ${ }^{\circ} \mathrm{C}$;

$t_{\text {well }}{ }^{-}$well wall temperature at the end of the considered operational period, ${ }^{\circ} \mathrm{C}$;

$t_{b g}$ - background ground temperature, ${ }^{\circ} \mathrm{C}$.

Fourier modulus:

$$
F_{O}=\frac{a \cdot \tau}{r_{\mathrm{C}}{ }^{2}}
$$

$a$ - temperature diffusivity coefficient, $\mathrm{m} 2 / \mathrm{sec}$;

$\tau$ - time, sec;

$r_{\mathrm{c}}-$ radius of the well, $\mathrm{m}$;

It is suggested that the dimensionless value of the heat flow should be attributed to the density of the Earth's background heat flow:

$$
Q=\frac{q_{\text {well }}}{q_{\text {earth }}}
$$

$q_{\text {well }}$ - heat flow density on the well wall during the calculation period under consideration, $\mathrm{W} / \mathrm{m} 2$;

$q_{\text {earth }}$ - density of earth's background heat flow, $\mathrm{W} / \mathrm{m} 2$.

For quantitative estimation of heat recovery degree at alternating mode of heat pump operation we propose to introduce regeneration factor:

$$
k_{p}=\frac{Q s}{Q d}
$$

$Q_{s}$ - amount of supply flow in the warm period of the year, $\mathrm{W}$;

$Q_{d} \quad-$ amount of diverted flow during the cold period of the year, W.

\section{Results}

It is obvious that increase of heat flux density corresponding to increase of heat load on well leads to increase of rock temperature surrounding well. At the same time, certain regularities of temperature change that correlate with known features of non-stationary heat exchange have been revealed. Intensive temperature growth is characteristic for Fo $<12000$ criterion values with further temperature stabilization. This value of Fo corresponds to Fo $=15000$. The received series of curves with sufficient degree of accuracy is approximated by polynomial of 2 nd degree, that corresponds to the way of presentation of known solutions of non-stationary heat conductivity.

Using methods of statistical processing, on the basis of the data presented in Fig. 4, the following criterion equation for calculation of dimensionless temperature of a well operating in a cyclic mode of seasonal operation of a heat supply system was obtained:

$$
\begin{gathered}
\theta=-5 \cdot 10^{-9} \cdot Q \cdot F o^{2}+ \\
+2 \cdot 10^{-8} F o \cdot Q+0,0003 \cdot Q+5,1
\end{gathered}
$$

Change of heat flow direction, which accompanies switching of heat pump operation mode from heating to conditioning, changes temperature mode of the rock surrounding the well, as it more realizes accumulating capabilities of the ground. Heat is regenerated by alternating heating and cooling of the rock surrounding the well. It is obvious that after the cycle of heat removal (1 year, 2 years) the rock surrounding the well will be in a supercooled state, i.e. for the subsequent release of heat into the rocks surrounding the well requires minimal energy consumption, which increases the energy efficiency of the unit.

It should be noted from the revealed features that the best technical and economic indicators of the system are achieved at the regeneration factor $\mathrm{k}_{\mathrm{P}}=1$

Consistent reversing of the heat pump results in a heat wave system that leads to changes in well temperature and affects the technical and economic parameters of the system. The results of the study led to the conclusion that the annual drop in ground temperature will be gradually reduced under regeneration conditions. This suggests that the regeneration process can compensate for the heat load. At the same time, the volume of rock surrounding the well, subject to changes in temperature regime, will expand every year. Processing of the obtained data made it possible to propose equation (13) taking into account the effect of heat regeneration.

$$
\begin{gathered}
\theta=-5 \cdot 10^{-9} \cdot Q \cdot F O^{2}+2 \cdot 10^{-8} F o \cdot Q+ \\
+0,0003 \cdot Q+5,1\left(0,0004 k_{p}+1,0\right)
\end{gathered}
$$

Research have shown that as a result of long-term operation of a geothermal well in a cyclic mode of thermal loading, there are changes of a temperature field of the rock surrounding a well, with effect of interference of thermal waves, leading to accumulation of heat.

\section{Discussion}

Based on the processing of the results obtained criterion equations for calculating the dimensionless temperature of the well at the time of completion of the cycle of heat supply or removal, as the corresponding largest temperature difference heat pump. The received equations allow to specify calculation of technical and 
economic indicators taking into account duration of geothermal well operation and its mode.

\section{References}

1. Global catalog of data on heat flow [Electronic resource]: the database contains information on Solid Earth Physics entering the World Data Center on Solid Earth Physics. Electron. Dan. - M., [2018]. Access Mode: http://www.wdcb.ru/sep/heat_flow/hf_cat_gl.ru.html - Title. from the screen. (the date of circulation is 09.12.2018) [in Russian].

2. G.P. Vasiliev, Heat supply of buildings and structures using low-grade thermal energy of the surface layers of the earth, Dis. Dr. those. Sciences. Moscow State University of Civil Engineering (2006)

3. N.Y. Saprykina, P.V. Yakovlev, Simulation of soil temperature field during long-term operation of lowpotential geothermal wells, Sixth International Scientific Forum of Young Scientists, Students and Schoolchildren "The Potential of Intellectually Gifted Youth to the Development of Science and Education" (April 25-28, 2017, Astrakhan./ Astrakhan: GAOU JSC AGASU [in Russian] (2017)

4. E.I. Boguslavsky, V.V. Fitzak, Technology and Economics of Development of Near-Surface Geothermal Resources, St. Petersburg: Journal of mining institute, 224 (2017).

5. P. Cui, X. Cui, Y. Li, Z. Man, Fang, Heat-recovery analysis of pile of heat-exothers with spiral coils, Applied Energy, 88, 4113-4119 (2011)

6. F. Al-Ajmi, The cooling potential of earth-air heat exchangers for domestic buildings in a desert climate, Building and Environment, 41, 235-244 (2006).

7. G. Changsheng, Numerical methods for temperature field about random heat source model of ground source heat pump, American Journal of Industrial Engineering, 1(2), 20-27 (2013).

8. P. Cui, Heat transfer analysis of pile geothermal heat exchangers with spiral coils, Applied Energy, 88, 4113-4119 (2011).

9. L. Lamarche, Analytical g-function for inclined boreholes in ground-source heat pump systems, Geothermics, 40, 241-249 (2011).

10. B. Nordell, Large-scale utilization of renewable energy requires energy storage, International Conference for Renewable Energies and Sustainable Development. Université Abou Bekr (2007).

11. O. Ozgener, Modelling and performance evaluation of ground source (geothermal) heat pump systems, Energy and Buildings, 39, 66 - 75 (2007).

12. Sadiq Zarrouk Katie McLean, Geothermal Well Test Analysis, 336 (Academic Press, 2019)

13. Ronald DiPippo, Geothermal Power Plants, 624 (Butterworth-Heinemann, 2012).
14. Ron DiPippo, Geothermal Power Generation, 854 (Woodhead Publishing, 2016).

15. R.M. Shoedarto, Specifying recharge zones and mechanisms of the transitional geothermal field through hydrogen and oxygen isotope analyses with consideration of water-rock interaction, Geothermics, 86, 101797 (2020)

16. Zhou, Kun, Performance assessment and technoeconomic optimization of ground source heat pump for residential heating and cooling: A case study of Nanjing, China, Sustainable Energy Technologies and Assessments, 40, 100782 (2020)

17. Liu, Xiling, Experimental study on the effect of strain rate on rock acoustic emission characteristics, International Journal of Rock Mechanics and Mining Sciences, 133, 104420 (2020)

18. N. Yu. Saprykina, Investigation of the formation of the temperature field of soil during the operation geothermal heat pumps under the influence of groundwaters, Russian Journal of Building Construction and Architecture, 4(36), 58-69 (2017).

19. N. Yu. Saprykina, Investigation of the Influence of the Modes of the Operation of a Geothermal Well with the Systems of Heat Supply and Air Conditioning in Combination with a Thermal Pump on the Temperature of a Soil Layer, Russian Journal of Building Construction and Architecture, 1(41), 38-50 (2019). 